\title{
Fragmentation and propulsive effect of shock wave lithotripsy in treatment of small renal calculi
}

\author{
Ammar Fadil Abid ${ }^{1 *}$ (D) and Nasser Sabah Hussein ${ }^{2}$
}

\begin{abstract}
Background: Small renal calculi are frequently observed in clinical practice, and chemo-lytic therapy has limited effects. The purpose of the study is to evaluate the effectiveness of extracorporeal shock wave lithotripsy (ESWL) in the treatment of small renal calculi.

Methods: We studied 60 patients with small renal stones from March 2017 to March 2019. After excluding eight patients with incomplete data, the remaining 52 patients were evaluated. Patients with symptomatic single or multiple stones of 6-8 $\mathrm{mm}$ in diameter or asymptomatic on ultrasound and kidney-ureter-bladder radiograph were eligible for inclusion. Small stones were treated by ESWL. The data were analyzed using the Statistical Packages for Social Sciences - version 25 (IBM Corporation).

Results: The mean age of the 52 patients was $34.5 \pm 9.5$ years. Forty-one (78.8\%) patients were symptomatic, while $11(21.2 \%)$ were asymptomatic. Forty-seven (90.4\%) had single small renal stones, while four patients had two stones (7.7\%) and only one patient had three stones (1.9\%). Forty-five stones were successfully treated by ESWL, while 13 stones failed to respond.

Conclusion: ESWL is a useful tool for treating small renal calculi; it works either by fragmenting the stones or by acting as a pushing force. However, further large prospective studies are needed to corroborate the above conclusions.
\end{abstract}

Keywords: ESWL, Small renal stone, Loin pain

\section{Introduction}

Urolithiasis affects 5 to $15 \%$ of the population worldwide [1-5]. It involves stones as small as a grain of sand or as large as a staghorn. Symptomatic or asymptomatic small renal stones that are $6-8 \mathrm{~mm}$ in diameter can either be treated by extracorporeal shock wave lithotripsy (ESWL) or retrograde flexible ureteroscopy [6-9]. The optimal treatment approach depends on the preferences of the physician and the patient, in addition to the availability of equipment.

\footnotetext{
*Correspondence: amarfadil@uomustansiriyah.edu.iq ${ }^{1}$ Urology Department, Medical College, Al Yarmouk Teaching Hospital, AL Mustansiriyah University, PO Box: 4356, Baghdad, Iraq Full list of author information is available at the end of the article
}

Small symptomatic and asymptomatic calculi are treated to achieve pain relief, stone elimination in shorter period than expectant therapy. Moreover, it might prevent the complications of renal colic, hematuria, infection or stone growth and reduce the need for invasive procedures $[7,9]$.

Many symptomatic small renal stones are treated expectantly. An empiric therapy (potassium citrate and thiazides) based on stone composition can reduce stone recurrence [10]. In stones visualized by kidney-ureterbladder radiographs (KUB), chemo-dissolution has limited applicability.

In this study, we aimed to evaluate the fragmentation and propulsive roles of ESWL in the treatment of small renal calculi. 


\section{Methods}

In this prospective study, we first included 60 patients with small renal stones who were admitted to our hospital/clinic from March 2017 to March 2019. Eight patients with incomplete data were excluded; thus, the remaining 52 patients were considered for further evaluation. Patients with symptomatic single or multiple stones of 6-8 $\mathrm{mm}$ diameter or asymptomatic on ultrasound (US) and $\backslash$ or KUB for at least 3 months were eligible for inclusion in our study (Figs. 1, 2). Informed written consents were obtained from all patients before they were offered the option of ESWL. The study had been submitted and approved by ethics committee (scientific committee of surgical department, Medical College, AL Mustansiryiah University.

Demographic data of the included patients are shown in Table 1. Prior to treatment with ESWL, all the patients underwent biochemical evaluation including urinalysis and renal function tests. Stone size was defined as the longest stone diameter on plain abdominal radiograph and ultrasonography for opaque and lucent stones, respectively.

ESWL was performed by using two lithotripters: Siemens lithoscope for opaque stones and Wolf piezoelectric for radiolucent stones, with focal size of $12 \mathrm{~mm}$ and focal depth of $160 \mathrm{~mm}$, in center with two lithotripter machine its useful to select the most appropriate device to maximize the success of stone fragmentation. All patients were treated in the supine position and were administered intramuscular diclofenac and tramadol 30 min before pre ESWL.

The therapy started at a low power of $14 \mathrm{kV}$, which was gradually increased up to $20 \mathrm{kV}$. The maximum number of shocks per session was 3500 , and the pulse frequency was 90 per minute. Post ESWL patients were advised to increase fluid intake, dissolution therapy (K-citrate) were used for lucent stone, while medical expulsive therapy

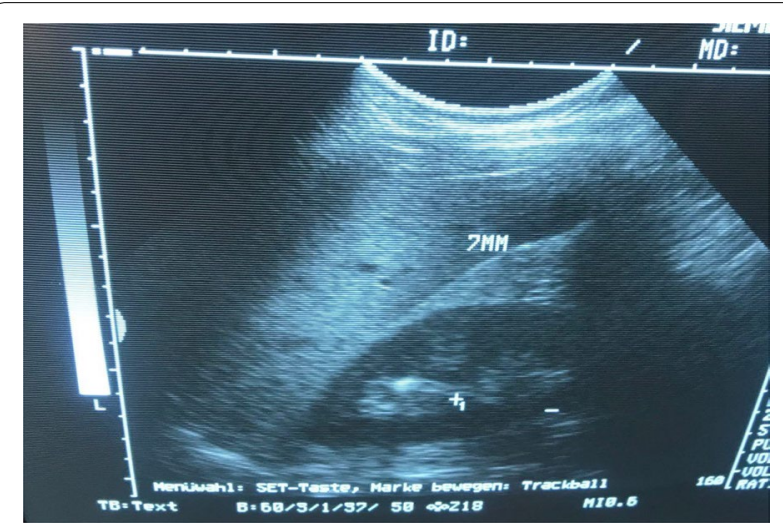

Fig. 1 Ultrasound right upper pole small renal stone

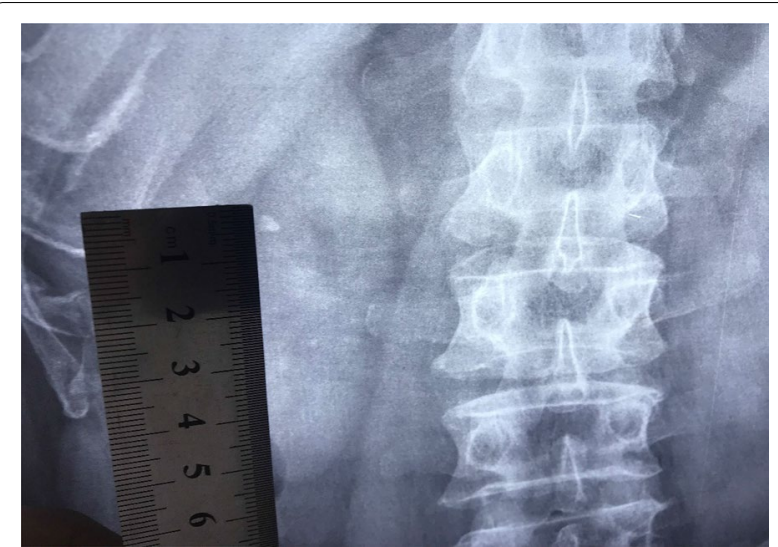

Fig. 2 KUB radiograph, small opaque stone

were not used. No ancillary procedures were utilized among studied group.

Follow-up studies included US and/or KUB radiograph to assess fragmentation and obstruction, and the ESWL session was repeated at 2 weeks after the previous one. Finally, patients were evaluated 3 months after the last lithotripsy session; repeated sessions were done if stone still present or partial fragmentation was detected.

In fifty-two patients 58 small stone treated with ESWL, $46(79.6 \%)$ stones had one session of shock wave lithotripsy, while $12(20.4 \%)$ stones had two or three session.

Table 1 Demographic data of patients with small renal stone

\begin{tabular}{lrr}
\hline Patients $(\boldsymbol{n = 5 2 )}$ & No & \% \\
\hline Age (years) & 16 & 30.8 \\
$20-29$ & 20 & 38.5 \\
$30-39$ & 11 & 21.2 \\
$40-49$ & 5 & 9.6 \\
$\geq 50$ years & & \\
Gender & 41 & 78.8 \\
Male & 11 & 21.2 \\
Female & & \\
Symptomatic & 41 & 78.8 \\
Yes & 11 & 21.2 \\
No & & \\
Number of stones & 47 & 90.4 \\
1 & 4 & 1.9 \\
2 & 1 & \\
3 & & 90.4 \\
Total number of stones $=58$ & & \\
PCS dilatation & 5 & \\
Yes & 47 & \\
No & & \\
\hline
\end{tabular}


We divided outcome of lithotripsy of small renal stones as follows:

1. Stone-free group in which the stones had either fragmented and passed or passed completely after being treated by the shock waves.

2. Non-responding groups in which the patients exhibited no response even after three sessions or the patients were unwilling to have further sessions after the failed first attempt. These patients were either offered treatment with another modality or were followed up.

\subsection{Statistical analysis}

The data were analyzed using the Statistical Packages for Social Sciences - version 25 (IBM Corporation). The significance of differences was tested using Pearson's Chi square test $\left(c^{2}\right.$-test $)$ with application of Yate's correction or Fisher's exact test, whenever applicable.

\section{Results}

The mean age of the 52 patients was $34.5 \pm 9.5$ years, and the age ranged from 20 to 60 years. Forty-one (78.8\%) patients had flank pain, while $11(21.2 \%)$ were asymptomatic.

A total of 58 stones were treated with ESWL. Of them, $47(90.4 \%)$ were single small renal stones. Four patients had two stones (7.7\%), and only one patient had three stones (1.9\%). Forty-five stones were successfully treated by ESWL, while 13 stones failed to respond to the treatment approach.

With regards to the distribution of the small stones, 5 were pelvic stones associated with hydronephrosis, 53 were calyceal stones, and $35(60 \%)$ were mid calyceal stones.

Of the 45 successfully treated stones, 37 stones were fragmented, and the 8 remaining stones migrated down the ureter as the shock waves served as a pushing force rather than fragmentation force (Figs. 3, 4, 5). Of these migrated stones, two further needed ESWL in situ, while the others passed spontaneously.

Among the factors studied included side, site, opacity, PCS dilatation, age, and number of ESWL session. Our findings revealed that the right-sided stones exhibited better statistically significant stone-free rate compared to the other side. Table 2 presents the renal stone characteristics and ESWL outcomes.

At the end of the final treatment session, 45 (77.6\%) stones were completely removed, and no fragmentation was observed in 13 (22.4\%) stones.

Complications during the treatment include pain as reported by 10 patients (19.2\%) who needed additional
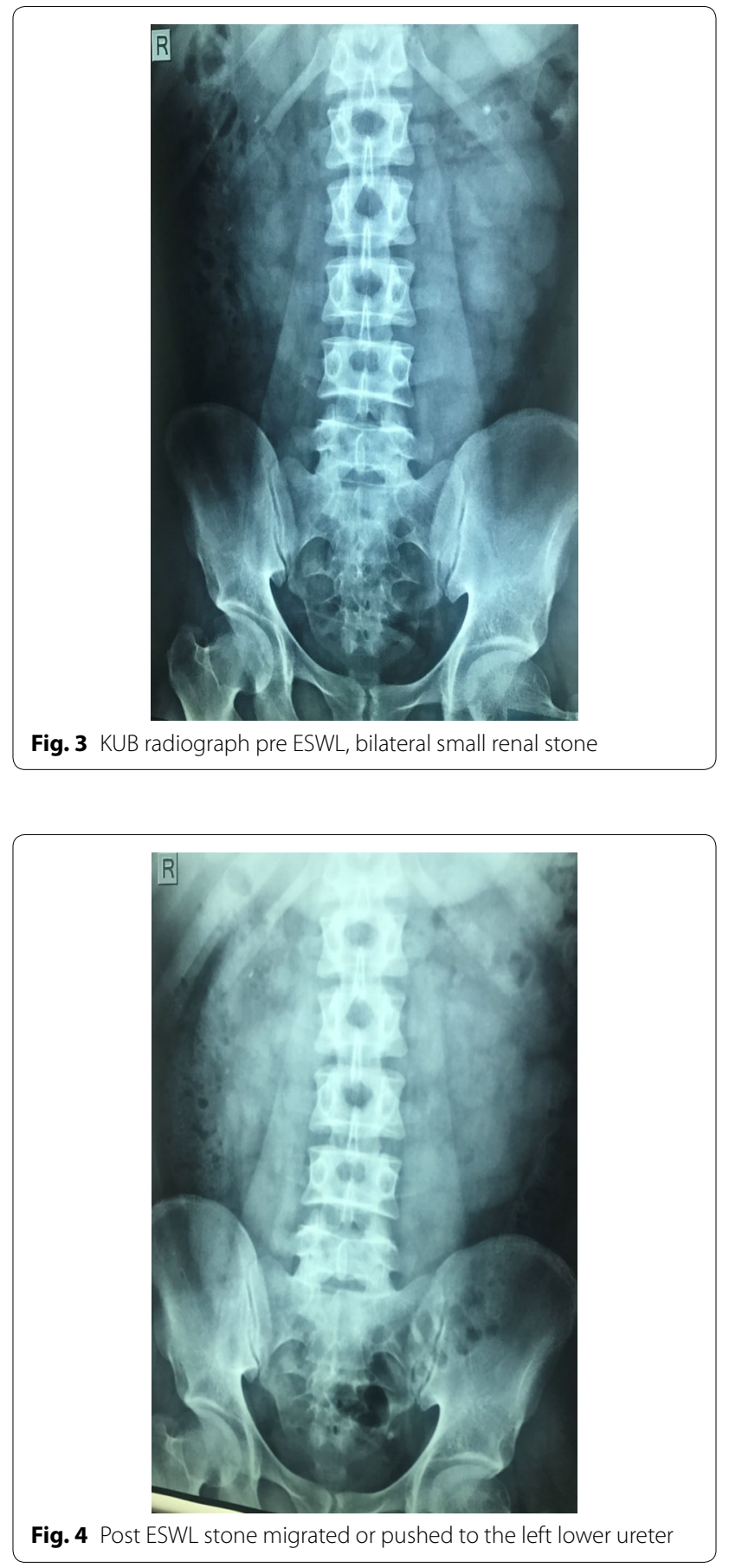

analgesia during the ESWL. Eight patients failed to attend the follow-up sessions.

\section{Discussions}

In this study, we used US and KUB radiographs for detecting stones in patients. The use of US alone for stone detection yields a sensitivity of $78.9 \%$ and a specificity of 


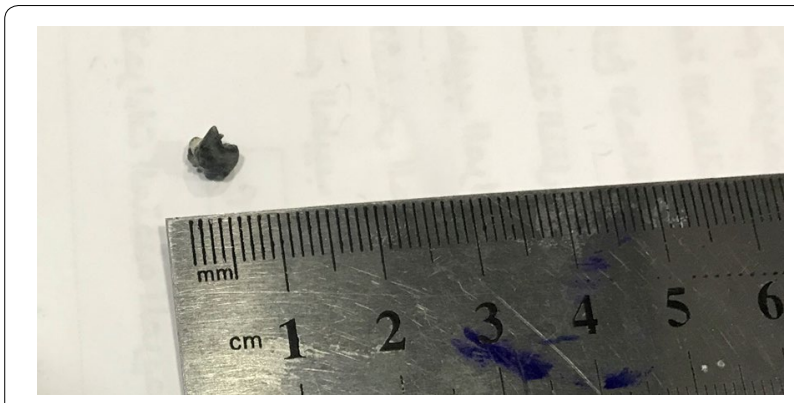

Fig. 5 Small stone passed post ESWL

Table 2 Renal stone characteristics and their ESWL outcomes

\begin{tabular}{|c|c|c|c|c|c|}
\hline \multirow[t]{3}{*}{ Stones $(n=58)$} & \multicolumn{4}{|c|}{ Outcome } & \multirow[t]{3}{*}{$P$ value } \\
\hline & \multicolumn{2}{|c|}{ Stone free } & \multicolumn{2}{|c|}{ No change } & \\
\hline & No & $\%$ & No & $\%$ & \\
\hline \multicolumn{6}{|l|}{ Side of stone } \\
\hline Right & 26 & 89.7 & 3 & 10.3 & \multirow[t]{2}{*}{$0.028^{*}$} \\
\hline Left & 19 & 65.5 & 10 & 34.5 & \\
\hline \multicolumn{6}{|l|}{ Site of stone } \\
\hline Calyx & 41 & 77.4 & 22.6 & 12 & \multirow[t]{2}{*}{0.892} \\
\hline Pelvis & 4 & 80.0 & 1 & 20.0 & \\
\hline \multicolumn{6}{|c|}{ Site of calyx stone $(n=53)$} \\
\hline Upper Calyx & 6 & 100 & - & - & \multirow[t]{3}{*}{0.232} \\
\hline Mid calyx & 21 & 70.0 & 9 & 30.0 & \\
\hline Lower calyx & 14 & 82.4 & 3 & 17.6 & \\
\hline \multicolumn{6}{|l|}{ Dilated PCS } \\
\hline Yes & 4 & 80.0 & 1 & 22.6 & \multirow[t]{2}{*}{0.892} \\
\hline No & 41 & 77.4 & 12 & 22.6 & \\
\hline \multicolumn{6}{|l|}{ Lucent or Opaque } \\
\hline Lucent & 17 & 73.9 & 6 & 26.1 & \multirow[t]{2}{*}{0.587} \\
\hline Opaque & 28 & 80.0 & 7 & 20.0 & \\
\hline \multicolumn{6}{|l|}{ Stone size $(\mathrm{mm})$} \\
\hline 6 & 4 & 100 & - & - & \multirow[t]{3}{*}{0.440} \\
\hline 7 & 15 & 71.4 & 6 & 28.6 & \\
\hline 8 & 26 & 78.8 & 7 & 21.2 & \\
\hline
\end{tabular}

83.7\%. In comparison, the combined use of US and KUB radiographs has a sensitivity of $89.9 \%[11,12]$.

US done by a single operator, Stone detected by ultrasound depend on presence of acoustic shadow, stone $\leq 5 \mathrm{~mm}$ does not produce shadow [13].

Fifty-eight (90.4\%) small stones were found to be single and $60.3 \%$ stones were mid calyceal in this study. Fortyone (78.8\%) patients had flank pain for at least 3 months; five pelvic stones were obstructive stones, while the others were non-obstructive. The reason for flank pain is not fully elucidated, but the pain subsided with ESWL.
Relief of pain after ESWL of non-obstructive renal stones might be multifactorial including stone-free status, the analgesic effect of shock wave on tissue "shock wave application can induce nerve fiber degeneration" [14]. Long-standing flank pain associated with small renal stones and no obvious obstruction is called small stone painful syndrome [8]. The rationale for treating small symptomatic and asymptomatic calculi by ESWL is to relive pain rapidly compared to the expectant therapy. Moreover, ESWL prevents the complications of hematuria, infection or stone growth and reduces the need for more invasive procedures with potentially higher morbidity $[7,9]$.

In our study, the stone-free rate was $77.6 \%$. In comparison, Gürbuz et al. reported $92.5 \%$ stone-free rate and found no statistical difference between ESWL and F-URS for treating small renal pelvic stones less than $10 \mathrm{~mm}$ in diameter [6].

The right-sided stones exhibited statistically significant stone-free rate n.26 (89.7\%) $P$ value 0.028 compared to the other side, as the right kidney inherent better image on ultrasound as the presence acoustic window of liver, consequently more precise targeting of stone in case of non-opaque stone, also less movement of right kidney in comparison to the left lead to better hit rate, in addition gas in the left colon might reduce efficiency of ESWL on left side. [15].

In this study, ESWL either fragmented the stones (31 stone) or served as a pushing force. A total of 7 stones were migrated down the ureter after ESWL; in these cases, the shock waves played as a pushing force rather than the fragmentation role.

This propulsive effect of ESWL is similar to other techniques were used like "focused ultrasound vibration or using external physical vibration Lithecbole" to enhance stone migration or what's called stone relocation $[3,16]$.

Eleven patients (21.2\%) exhibited asymptomatic renal stones that were treated by ESWL, and six of them became stone-free.

In many series, the surgical intervention required in asymptomatic calyceal stones that ranged $19-25 \%[17$, 18].

A previous study performed 4 year mean follow-up of 293 patients to evaluate the natural history of asymptomatic renal calculi and reported that ESWL was the primary therapy in 33 patients and ureteroscopy in 3 patients [19].

Thirteen stones of studied group failed to respond to ESWL. Since stone response to ESWL cannot be predicted accurately, asymptomatic patients are offered the options of RIRS or observation. Some of the advantages of ESWL include shorter operative time and hospital stay in comparison to RIRS [20]. 
The need for long-term follow-up for asymptomatic calyceal stones and the finding that painless silent hydronephrosis developed in $2 \%$ of patients raise concern and mandate active treatment rather than the wait-and-see approach [17].

The EAU 2018 guidelines recommend the treatment of renal stones in patients with stone growth $(>5 \mathrm{~mm}$ ) based on de novo obstruction, patient preference, social situation (professional or traveling), solitary kidneys, women planning on getting pregnant and in patients with chronic pain [21].

Prophylactic ESWL in asymptomatic renal calyceal stones, as reported by Keeleys et al., exhibited no advantages for patients in terms of stone-free rate, quality of life. However, the authors included only opaque lower calyceal stones that were within $15 \mathrm{~mm}$ in size [7].

In brief, we recommend using KUB radiography to ascertain whether the stones are opaque or lucent to help in decision of therapy. Symptomatic small renal stones visualized by KUB radiograph the role of empiric are limited.

Finally, modifying the technique and involving urologist actively in lithotripsy unit can improve ESWL outcome. ESWL will keep its role as the single noninvasive treatment in small stone management [22].

The limitation of this study is that two lithotripters with different mechanisms of stone fragmentation were used.

\section{Conclusion}

Extracorporeal shock wave lithotripsy is a useful tool for treating small renal calculi as it works either by fragmenting the stones or by acting as a pushing force. However, further large prospective studies are needed to corroborate the above conclusions.

\section{Abbreviations \\ ESWL: Extracorporeal shock wave lithotripsy; US: ultrasound; KUB: kidney ureter and bladder radiograph; RIRS: retrograde intrarenal surgery for stone; PCS: pelvi-calyceal system; mm: millimeter.}

\section{Acknowledgements}

We thank the working staff in shock wave unit for their assistance.

\section{Authors' contributions}

AF analyzed and interpreted the patient data regarding the renal stone and their response to shock wave lithotripsy. NH performed the statistical work, and was a major contributor in writing the manuscript. All authors read and approved the final manuscript.

\section{Availability of data and materials}

The datasets used and/or analyzed during the current study are available from the corresponding author on reasonable request.

\section{Ethics approval and consent to participate}

This study performed in accordance with the Declaration of Helsinki and had been submitted and approved by ethics committee (scientific committee of surgical department, Medical College, AL Mustansiryiah University). The reference number is not available.Informed written consent from all participate were obtained.

\section{Consent for publication}

Written informed consent for the publication of these details had been obtained from the participants.

\section{Competing interests}

The authors declare that they have no competing interests.

\section{Author details}

${ }^{1}$ Urology Department, Medical College, Al Yarmouk Teaching Hospital, AL Mustansiriyah University, PO Box: 4356, Baghdad, Iraq. ${ }^{2}$ Department of Urology, Al Karama Teaching Hospital, Baghdad, Iraq.

Received: 21 February 2020 Accepted: 24 August 2020

Published online: 03 November 2020

\section{References}

1. Moe OW (2006) Kidney stones. Pathophysiology and medical management. Lancet 367:333-344

2. Farhan M, Nazim SM, Salam B et al (2015) prospective evaluation of outcome of percutaneous nephrolithotomy using the 'STONE' nephrolithometry score: a single -center experience. Arab J Urol 13(4):264-269. https:// doi.org/10.1016/j.aju.2015.07.006

3. Wu W, Yang Zhong, Changbao Xu et al (2017) External physical vibration lithecbole promotes the clearance of upper urinary stones after rethrograde intrarenal surgery: a prospective, multicenter, randomized controlled trial. J Urol 197:1289-1295

4. Scales CD Jr et al (2012) Prevalence of kidney stones in the United States. Eur Urol 62(1):160-165

5. McCarthy CJ, Baliyan V, Kordbacheh H (2016) Radiology of renal stone disease. Int J Surg 36:638-646

6. Gürbuz ZG, Şener NC, Vuruşkan E, Deniz ME, Gürlen G, Ortoğlu F (2018) Small renal pelvis stones: shock wave lithotripsy or flexible ureteroscopy? A match-pair analysis. Turk J Urol 4:1-4. https://doi.org/10.5152/ tud.2018.70094

7. Keeley FX, Tilling K, Elves A, Menezes P, Wills M, Rao N, Feneley R (2001) Preliminary results of a randomized controlled trial of prophylactic shock wave lithotripsy for small asymptomatic renal calyceal stones. BJU Int 87(1):1-8. https://doi.org/10.1046/j.1464-410x.2001.00781.x

8. Jura YH, Lahey S, Eisner BH, Dretker SP (2013) Ureteroscopic treatment of patients with small, painful, non-obstructing renal stones: the small stone syndrome. Clin Nephrol 79(1):45-49. https://doi.org/10.5414/CN107637

9. Ferraro PM, Pinto F, Gambaro G (2018) Shock-wave lithotripsy or ureterorenoscopy for renal stones? Clin Kidney J 11(3):362-363. https://doi. org/10.1093/ckj/sfy025

10. Goldfarb DS (2019) Empiric therapy for kidney stones. Urolithiasis 47(1):107-113

11. Kanno T, Kubota M, Funada S, Okada T (2017) The utility of the kidneysureters-bladder radiograph as the sole imaging modality and its combination with ultrasonography for the detection of renal stones. Urology 104:40-44

12. Kanno T, Toru Kubota M, Sakamoto H et al (2014) The efficacy of ultrasonography for the detection of renal stone. Urology 84(2):285-288

13. Dai JC, Dunmire B, Sternberg KM et al (2018) Retrospective comparison of measured stone size and posterior acoustic shadow width in clinical ultrasound images. World J Urol 36(5):727-732. https://doi.org/10.1007/ s00345-017-2156-8

14. Takahashi N, Ohtori S, Saisu T, Moriya H, Wada Y (2006) Second application of low-energy shock waves has a cumulative effect on free nerve endings. Clin Orthop Relat Res 443:315-319

15. Chaussy CG, Tiselius HG (2018) How can and should we optimize extracorporeal shockwave lithotripsy? Urolithiasis 46:3-17. https://doi. org/10.1007/s00240-017-1020-z

16. Abrol N, Kekre NS (2015) Focused ultrasound guided relocation of kidney stones. Indian J Urol 31(1):28-32. https://doi.org/10.4103/09701591.139577 
17. Darrad MP, Yallappa S, Metcalfe J, Subramonian K (2018) The natural history of asymptomatic calyceal stones. BJU Int 122(2):263-269. https://doi. org/10.1111/bju.14354

18. Dropkin BM, Moses RA, Sharma D, Pais VM Jr (2015) The natural history of nonobstructing asymptomatic renal stones managed with active surveillance. J Urol 193(4):1265-1269

19. Li X, Zhu W, Lam W, Yue Y, Duan H, Zeng G (2018) Outcomes of long-term follow-up of asymptomatic renal stones and prediction of stone-related events. BJU Int 32(5):371-379. https://doi.org/10.1089/end.2017.0848

20. Junbo L, Yugen L, Guo J, Jing H, Ruichao Y, Tao W (2019) Retrograde intrarenal surgery vs. percutaneous nephrolithotomy vs. extracorporeal shock wave lithotripsy for lower pole renal stones 10-20 mm: a meta-analysis and systematic review. Urol J 16(2):97-106. https://doi.org/10.22037/ uj.v0i0.4681

21. European Association of Urology Guidelines on urolithiasis (2018). http:// uroweb.org/guideline/urolithiasis/. Accessed 18 Dec 2019

22. Basulto-Martínez M, Klein I, Gutiérrez-Aceves J (2019) The role of extracorporeal shock wave lithotripsy in the future of stone management. Curr Opin Urol 29(2):96-102

\section{Publisher's Note}

Springer Nature remains neutral with regard to jurisdictional claims in published maps and institutional affiliations.

\section{Submit your manuscript to a SpringerOpen ${ }^{\circ}$ journal and benefit from:}

- Convenient online submission

- Rigorous peer review

- Open access: articles freely available online

- High visibility within the field

- Retaining the copyright to your article

Submit your next manuscript at springeropen.com 